\title{
Enterprise Anti-Crisis Strategy
}

\author{
$\mathrm{PhD}$ Hamdamov Omonullo Abdumannobov A'lobek \\ 1.Department of Financial Management, Tashkent Institute of Finance 60A, Amir temur street, 100000, \\ Tashkent, Uzbekistan \\ 2.Department of Finance, Tashkent Institute of Finance, 60A, Amir temur street, Tashkent, Uzbekistan
}

\begin{abstract}
In the paper economic foundations and the stages of development of anti-crisis management strategy were described. And scientifically proven that anti-crisis strategy is an important element of the corporate financial management.
\end{abstract}

Keywords: strategy, anti-crisis management strategy, the factors of the crisis, characteristics of the anti-crisis management, reorganization, restructuring, economic cycle.

DOI: $10.7176 /$ EJBM/11-11-05

Publication date: April $30^{\text {th }} 2019$

Anti-crisis management is one of the most important elements of financial management. Development and implementation of an anti-crisis strategy is becoming one of the pressing issues of business management decisions. Increased attention to this issue by the company's specialists depends on many objective factors. Under the conditions of the market economy, the state of the crisis is a phenomenon in the business of any enterprise, requiring the financial managers of the company to change in many aspects of routine management directions and to organize future activities. One of the important points to be taken into consideration in the market economy is the existence of the probability of a crisis situation at any stage of the economic cycle of the enterprises. Elimination of crisis consequences at the enterprise can be accomplished by introducing anti-crisis measures. Identifying and analyzing the causes of the crisis in the enterprise, studying the factors causing the crisis, developing anti-crisis measures and implementing them constitute the basis of the anti-crisis strategy.

As we know, the strategy is a general action plan, a set of measures, in general systems of financial management, production, human resources management. An anti-crisis strategy includes the steps to be taken to analyze the causes of the crisis and to evaluate and control the consequences of anti-crisis programs and strategies. anti-crisis strategy.

Anti-crisis financial management - crisis forecasting, monitoring, learning causes of the crisis, the use of crisis factors for the development of the enterprise, reducing negative consequences of the crisis. In other words, the nature of the anti-crisis financial management can be characterized by:

$>$ First, a set of measures aimed at preventing the entity from falling into a crisis, analyzing the strengths and weaknesses of the enterprise, assessing bankruptcy probabilities, risk management (assessment, assessment and elimination), introducing the necessary system of measures and the like;

$>$ And secondly, is an element of corporate finance management, which is aimed at removing the company from crisis through judicial rehabilitation or restructuring.

An anti-crisis financial management system can be as effective or ineffective as any other management system. Its effectiveness is defined by the extent to which problems such as preventing, eradicating, mitigating the effects of the crisis or the positive impact of the crisis can be solved. Therefore, the role of anti-crisis financial management in the overall corporate governance system, and the designation of its specific goals and objectives are reasonable (Figure 1). 


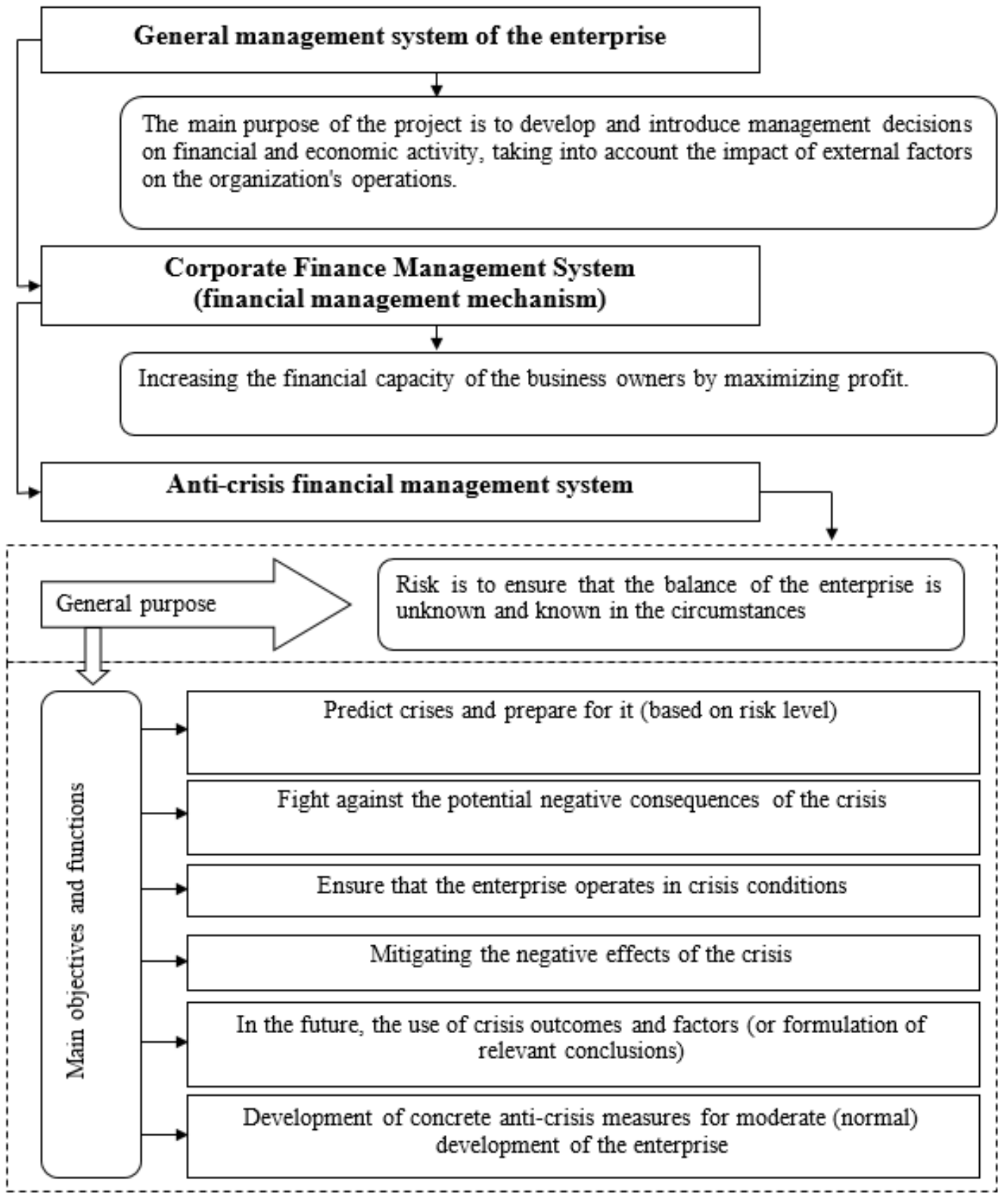

Figure 1. Organization of anti-crisis financial management in corporate governance ${ }^{1}$

This formulation of the anti-crisis financial management system plays a crucial role in elaborating and implementing sound management decisions in order to achieve the objectives of the enterprise in the context of various external factors. Creating a basis for activities that need to be addressed at each stage of the Anti-crisis Financial Management Task at all stages of its implementation will be instrumental in preventing the bankruptcy of the enterprise.

One of the main criteria for effective anti-crisis management in the enterprise is to form strategic anti-crisis objectives. In the above picture, we have considered the mission, goals and objectives of the anti-crisis financial management, the overall objective of the business impacts and their impact on the operations of the enterprise. According to the opinion of Russian economists, led by S. Kovan, the sequence of determining the factors considered in the process of forming strategic anti-crisis goals can be expressed as follows (Figure 2).

\footnotetext{
${ }^{1}$ Written by the author
} 
According to the picture, the enterprise will first learn the factors that cause the crisis and the negative consequences. The extent to which these factors influence the occurrence of the crisis is assessed and selected for analysis. Factors that do not seriously affect the emergence of the crisis are studied within the scope of the functions of the general management entities, while the rest are deeply analyzed. In the absence of the ability to control some of these factors, these factors will also be delayed for further study in the next stages of the functions of management entities, while others will be considered in future development of the anti-crisis strategy. It also analyzes whether the selected factors can be governed by the financial, legal, or social capabilities of an enterprise. For example, the impact of an enterprise on the factors causing a crisis is related to financial issues but, if it is not possible to attract financial resources as a result of high creditors' debts, tax burden, and other mandatory payments to the budget, this may indicate that it can not eliminate this factor at the enterprise level .

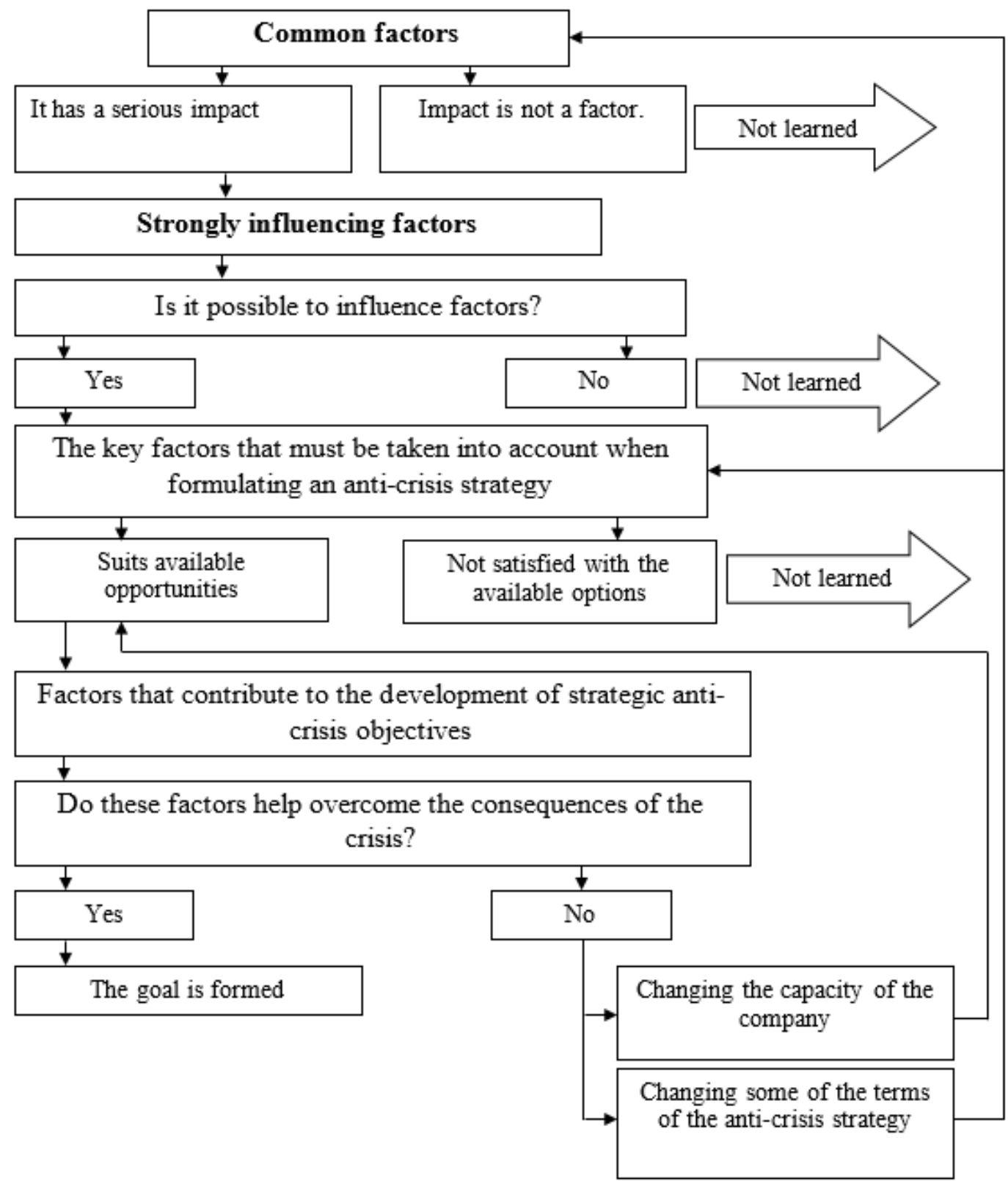

Figure 2. The procedure for determining the factors to be taken into account when formulating strategic anti-crisis objectives. ${ }^{1}$

In our opinion, the importance and necessity of anti-crisis financial management in enterprises should be

${ }^{1}$ С.Е.Кован, Л.П.Мокрова, А.Н.Ряховская. Теория антикризисного управления предприятием:учебное пособие - М.: КНОРУС, 2009 - c. 86 
established not only during the crisis, but also at all stages of the economic cycle of the enterprise from the very beginning of the enterprise. Enterprises can overcome various economic cycle stages throughout their operations. Of course, each cycle of development involves business management, financial planning, the need for financial resources, production volumes, and so forth. Based on the characteristics of the economic development cycle of corporate financial managers, therefore, the anti-crisis financial management should formulate the strategy. Businesses can take stages of stable, unstable (pre-crisis or post-crisis) or crisis situations throughout their business. The share of anti-crisis financial management in the overall management system can either expand or decrease, depending on the stage of its development (Figure 3).

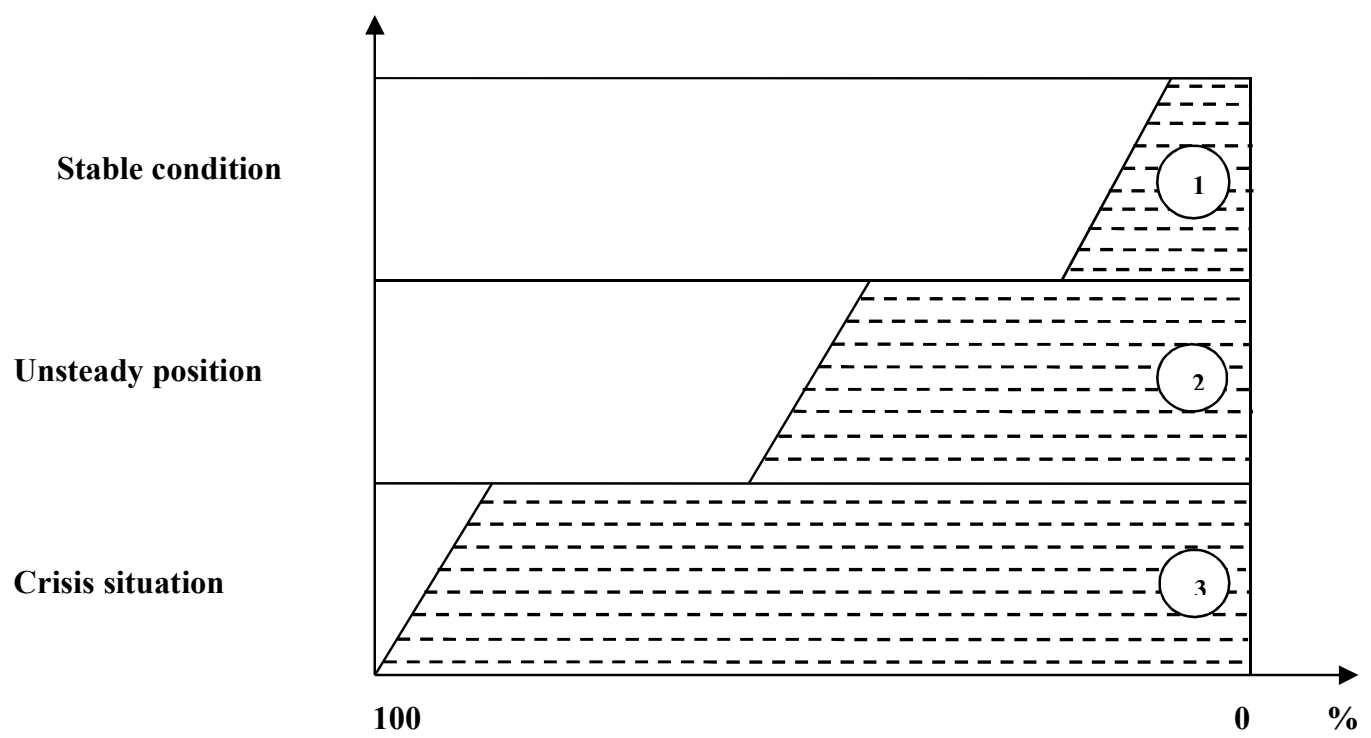

1- anti-crisis monitoring; 2- regulation of anti-crisis management;

3- anti-crisis management.

Figure 3. The share of anti-crisis management in various phases of the corporate economic cycle ${ }^{1}$

The main objective of the anti-crisis management in the sustainable economic cycle of the enterprise is to prepare for and prepare for preventive measures that may arise. An anti-crisis monitoring was organized during this period, and the main purpose of this is to determine the negative impact of the crisis on time and prepare for the mitigation of its consequences. In this process, the share of anti-crisis management in the total control system is relatively small.

Assessment of the enterprise as unstable, indicates that the anti-crisis management has passed to the regulatory phase. During this period, measures are taken to prevent the deepening and development of the crisis and to strengthen the situation. Additionally, managing directors' decisions, which require high level of expertise and experience from managers of the given period, can lead to the development of the enterprise from moderate to moderate development or crisis. In this period, the share of anti-crisis management in the overall corporate governance system is equal to the proportion. One of the main functions of the anti-crisis financial management in the crisis is to study the factors leading to the crisis in order to ensure the continuity of the company's operations, minimize negative consequences and costs, and to further develop the enterprise, and take concrete measures to eliminate them on the basis of analysis.

Based on the above picture, we can distinguish between the entity's stable management system and the crisis management system (Table 1).

The issues that need to be addressed within the framework of the Anti-crisis financial management are diverse and can be classified according to the following characteristics:

1. Stages of development of the crisis:

$>$ predicting the crisis situation;

$>$ elimination of the crisis;

$>$ ensuring the operation of the enterprise in crisis conditions;

$>$ ensuring that the crisis is extinguished;

\footnotetext{
${ }^{1}$ С.Е.Кован, Л.П.Мокрова, А.Н.Ряховская. Теория антикризисного управления предприятием:учебное пособие - М.: КНОРУС, 2009 - c. 26
} 
$>$ end the crisis

Table 1

Key differences of the anti-crisis financial management with sustainable management

\begin{tabular}{|l|c|c|}
\hline \multicolumn{1}{|c|}{ Indicators } & Stable condition & Crisis situation \\
\hline Purpose of management & $\begin{array}{c}\text { Increasing the efficiency of the } \\
\text { enterprise's economic activities }\end{array}$ & $\begin{array}{c}\text { Minimizing the negative effects of } \\
\text { the crisis }\end{array}$ \\
\hline $\begin{array}{l}\text { Use of resources } \\
\text { environment }\end{array}$ & $\begin{array}{c}\text { In the established order - on the } \\
\text { basis of planning }\end{array}$ & Failure - on the basis of savings \\
\hline Description of internal status & Convenient and positive & Uncomfortable and negative \\
\hline The result & $\begin{array}{c}\text { Increase in performance and } \\
\text { sustainability indicators }\end{array}$ & $\begin{array}{c}\text { Developing the enterprise from } \\
\text { crisis to development } \\
\text { state of affairs }\end{array}$ \\
\hline
\end{tabular}

1. With regard to the anti-crisis measures:

$>$ methodological;

$>$ financial - economic;

$>$ legal and organizational;

$>$ socio - psychological.

2. On management techniques:

$>$ search of data (reliability);

$>$ development of business models and various situations (variants) under crisis conditions;

$>$ developing anti-crisis management decisions.

3. Applied tools:

$>$ marketing (in the context of resource constraints and attractiveness problems);

$>$ diversification;

$>$ rehabilitation or restructuring;

$>$ anti-crisis investment and innovation policy;

$>$ employee, staff selection;

$>$ conflict, conflict management.

Based on the above, the anti-crisis strategies can be divided into three major groups: crisis outcomes, business recovery and development strategies. The choice of strategy is determined in each case taking into account the influence of many external and internal factors, and the effectiveness of the anti-crisis management depends on the precise choice of the anti-crisis strategy.

An effective anti-recessionary strategy is not only dependent on its methodological basis, but also on the ability of employees involved in the process of developing and implementing this process to perfectly comprehend their degree of professional skill, level of preparation, ability to properly define tasks and responsibilities, the factors that are most likely to depend on. At present, the development of the structure of governance in the practice of the developed countries' companies will focus on the establishment of the state of the "anti-crisis financial manager". We think that this practice can be used efficiently in the practice of big companies, first of all it will bring to the development of mechanism which can shape the strategy of fighting against crisis, then it will play a vital role in the preventation of the economic poor situations of companies, going into crisis through using all existing financial resources and social unstability.

\section{References}

1. Law of the Republic of Uzbekistan About bankruptcy April 24, 2003

2. Zub A.T., Panina E.V. Crisis management in organization: a tutorial M .: INFRA - M, $2007-256 \mathrm{p}$.

3. Kovan, S.E., Mokrova, L.P., Ryakhovskaya A.N. Theory of enterprise crisis management: a tutorial - M .: KNORUS, $2009-160 p$.

4. Toshmurodova B., Xamdamov O. Financial Management. Educational manual. Tashkent "EconomyFinance" 2012 - 160 p. Theory of enterprise crisis management 